\title{
Laudatio
}

\section{Gilbert Thomas Thiel: Recipient of the Volhard Medal 2000}

Professor Gilbert Thomas Thiel, the nestor of Swiss nephrology and renal transplantation, is honored with the Franz-Volhard-Medal by the Gesellschaft für Nephrologie.

Professor Thiel was born in Zürich, in 1934, and studied medicine in Zürich, Paris and Marburg. In 1959, he received his medical diploma, followed by training at the Department of Pathology in Zürich (1960-1961) and the Department of Internal Medicine of the City Hospital in Zürich-Waid (1961-965). From 1965 to 1967, he was research fellow at John P. Merrill's laboratory at the Peter Bent Brigham Hospital (Division of Nephrology), Harvard Medical School, Boston (USA), followed by training as clinical fellow of Professor B. Scribner at the Division of Nephrology, Washington University, Seattle (USA). In 1969, he was elected as head of the Department of Organ Transplantation at the Bürgerspital, University of Basel (Switzerland). In 1985, he became chief of the Division of Nephrology, Department of Medicine, at the Kantonsspital, University of Basel. He remained the head of this institution until his retirement in August 1999.

Professor Thiel was elected as president of several societies (Schweizerischen Gesellschaft für Nephrologie 1977-1979, Gesellschaft für Nephrologie 1980-1982, Arbeitsgruppe Nierentransplantation Swiss Transplant 1988-1989, Transplantationskommission der Schweizerischen Gesellschaft für Nephrologie 1994-1999, European Society for Organtransplantation 1995-1997, Leitungsgruppe "Implantate, Transplantate" des Schweizerischen Nationalfonds 1984-present); in 2000, he was elected copresident of the ethics committee of the University of Basel.

Professor Thiel published numerous articles in leading international journals. His clinical and experimental work contributed significantly to the scientific and clinical progress in nephrology and renal transplantation.

In Boston, Professor Thiel began toying with renal micropuncture techniques and developed the model of

\begin{tabular}{ll}
\hline KARGER & ( ) 2000 S. Karger AG, Basel \\
Fax +41 61 306 1234 $34-4096 / 00 / 0235 \$ 17.50 / 0$ \\
$\begin{array}{l}\text { E-Mail karger@ karger.ch } \\
\text { www.karger.com }\end{array}$ & Accessible online at:
\end{tabular}

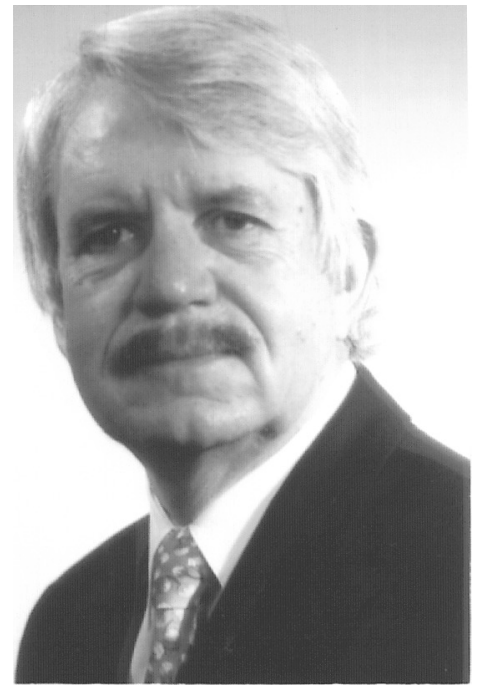

glycerol-induced acute renal failure. He brought the renal micropuncture technique to his laboratory in Basel and introduced other experimental models (toxic, ischemic) of acute renal failure. A further topic in his research was renal tubular obstruction.

Clinically, one of his main interests was renal transplantation, particularly in patients with diabetic nephropathy. He organized and participated in many multicenter studies using new immunosuppressive drugs such as the first cyclosporine study in 1981, mycophenolate mofetil, tacrolimus and rapamycin including also monoclonal or polyclonal antibodies. Professor Thiel developed one of the first European programs on emotionally motivated organ donation.

He pioneered the analysis of urinary sediment and was one of the first describing dysmorphic (glomerular) erythrocytes. In one of his lectures on the occasion of the Congress of the Society of Nephrology in Germany, he has coined the saying 
that "A nephrologist who is unable to analyze the urinary sediment is like a cardiologist who is unable to perform heart auscultation".

Professor Thiel performed extensive clinical and experimental studies on cyclosporine nephrotoxicity and the importance of Polyomavirus infection after renal transplantation in close collaboration with Professor Mihatsch (head of the Department of Pathology at the University of Basel).

Professor Thiel is a born teacher who impresses with his energy as well as clinical and scientific competence and integrity. I have started training in nephrology at the time when Professor Thiel was elected for the chair of nephrology at the University of Freiburg/Germany, a position which he did not accept in order to continue his clinical and experimental work at the University of Basel. For me he was and still is an outstanding clinician and scientist, and of strong, impressive personality. I am particularly proud to have been elected to honor this leading nephrologist on behalf of the Gesellschaft für Nephrologie by giving him the Franz-Volhard-Medal.

Walter H. Hörl, Wien 